\title{
SMEs' PERFORMANCE EVALUATION AND OPTIMIZATION BASED ON DEA AND CFI
}

\author{
Zhao Shi ${ }^{1}$, Josu Takala ${ }^{1}$, Matti Muhos ${ }^{2}$, Jyrki Poikkimaki ${ }^{3}$, Yang Chen ${ }^{1}$ \\ 1 University of Vaasa, Department of Production, Finland \\ ${ }^{2}$ University of Oulu, Department of Industrial Engineering and Management, Finland \\ ${ }^{3}$ VTT, Technical Research Centre of Finland, Finland
}

Corresponding author:

Josu Takala

University of Vaasa

Department of Production

FIN-65101 Vaasa, Finland

phone: +358-6-3248 448

e-mail: josu.takala@uwasa.fi

Received: 27 November 2012 Accepted: 12 February 2013

\begin{abstract}
It is a core content of enterprise performance research evaluating and comparing enterprise performance in dynamic environment. In allusion to this problem, a variety of enterprise performance assessment methods and indexes systems are proposed. Data envelopment analysis (DEA) is a kind of effective mathematical model which is used for comparing the performance among enterprises or different units inside an enterprise, based on the real-world data. Through comparing the performance, DEA can evaluate the enterprise performance from scale effectiveness and technological effectiveness, and then get the performance optimization goals. Critical Factor Index (CFI) is a new enterprise performance assessment method proposed in recent years. This method, based on the performance perception of business leaders or staffs, evaluates the enterprise performance in different dimensions, and then gets the optimization strategy of enterprise resource allocation to improve integrated enterprise performance. This paper has structured a new evaluation and optimization system for performance of small and medium-sized enterprises (SMEs), which combine properly the DEA and CFI method to evaluate and optimize the SMEs' performance comprehensively, and has confirm this system with data of 5 Finnish SMEs.
\end{abstract}

KEYWORDS

data envelopment analysis (DEA), critical Factor Index (CFI), small and medium-sized enterprises (SMEs), performance evaluation, optimization.

\section{Introduction}

The unit of analysis in this study is a manufacturing focused Small and Medium-sized Enterprise (SME). The definition of SME is different in different contexts. The US context offers multiple definitions of SME depending on the industry. For example, in some industries, SME is a company having less than 500 employees. In the European context, the SME is a company having less than 250 employees. This difference on definitions needs to be taken into account. Ayyagari et al. [1] covers this topic in his globally focused, statistical study on SMEs (p. 416): The term SME covers a wide range of definitions and measures, varying from country to country and vary- ing between sources reporting SME statistics. Some of the commonly used criteria are the number of employees, total net assets, sales, and investment level. However, the most common basis for definition is employment, and here again, there is variation in defining the upper and lower size limit of an SME. Despite this variance a large number of sources define an SME to have a cut-off of 250 employees [1]. Because of the case context, the European definition is utilised. Within the SME category, the European Union defines medium sized firms as having 50-249 employees, small firms as having 10-49 employees, and micro firms as having 0-9 employees [2].

In the recent literature, Small- and medium sized companies (SME's) are considered to be an impor- 
tant and integral part of every country's economy; the fastest growing sector of many economies, more flexible and adaptable in terms of structure and having a faster speed of response than larger organizations [3]. SMEs are often associated with a higher economic growth of nations [4]. The impact of SMEs on employment is significant [5]. On the other hand, compared to large enterprises, SMEs typically have fewer financial resources, lower technical expertise, and more limited management skills [6]. A large SME sector as such does not directly cause economic growth, but is indeed a key characteristic of successful economies. A successful SME sector can be considered a vital part of the growth and development in sparsely populated regions [7]. The 'early stages' of firms is a critical period for their survival and success as well as significant portion of firms fail during their early years of existence. Serving this group of companies well is an important challenge for public business services.

The companies analysed in this study are located in the Oulu South region. The region is located in Finland in the southern part of Northern Ostrobothnia. Oulu South is not a governmental unit or area-It was formed to increase inter-municipal co-operation and to gain the critical mass for national and international competitiveness. The region consists of three sub regions and 14 municipalities with about 90000 inhabitants. Oulu South is one of the main rural areas in Finland. Oulu South is characterized as an entrepreneurial and industrialized countryside, which offers one of the lowest employment rates in northern Finland. The demographic challenge is emigration from the area. On the other hand, the proportion of young people seems to remain high because of high birth rate. There are about 4600 active companies in Oulu South; the majority of them (95\%) are micro-sized companies.

\section{Research Methodologies}

\section{Analytical model: System of SMEs' Performance Evaluation and Optimization}

As a kind of Sense \& Respond model, Critical Factor Index (CFI) model can evaluate and balance the internal resources of enterprise in every aspect to improve the utilization efficiency of resource [8]. But CFI model still have three problems in SMEs' performance evaluation and optimization. First, CFI model mainly evaluates the resource allocation performance inside the enterprise based on the comparison among the indexes within enterprise. But it cannot evaluate resource performance in the whole or dimension level, especially can't compare the performance among enterprises. Second, CFI model can determine the critical indexes very well, but cannot confirm the excess input indexes. Third, CFI model mainly evaluates indexes from the view of resource input, but not from the view of efficiency of resource utilization. As a kind of performance evaluation model based on accurate data, DEA can evaluate the efficiency of resource utilization and the trend of resource input changes affecting performance on the base of performance comparison among dimensions. Therefore, the joint usage of DEA and CFI method can structure a complete system which can simultaneously evaluate and optimize SMEs' performance from the view of resource input and efficiency of resource utilization.

\section{(1) Index System of SMEs' Performance Evaluation and Optimization}

The SMEs' performance can be evaluated from three dimensions: dynamic capability, technological innovation capability and enterprise competitiveness.

Dynamic capability is mainly set for enterprise flexibility evaluation in resource and decision. It is mainly measured by the performance of adaptive process of enterprise in environmental changes. Dynamic capability is an important aspect of comprehensive performance of enterprises. At present, rapidly changing global business environment has set higher requirements in environment adaptability, rapid response capability and risk decision-making capacity to enterprises, especially to SMEs [9]. Compared with large enterprises, SMEs have the characteristics of smaller size, simple organization structure, fewer available resources and so on. These characteristics has caused that their risk resistance capacity is weaker and organization flexibility is stronger. Therefore, in face of the environmental changes, avoiding risk and adapting to the environment through rapid strategic realignment is the optimal choice of SMEs. And dynamic capability has become a decisive factor for survival and development of SMEs.

Technological innovation capability (ETIC) is mainly set for enterprise performance evaluation in technological innovation and keeping technological competitiveness. It is mainly measured by the performance of input-output efficiency in technological innovation and technological innovation system. For modern enterprises, the technological innovation is undoubtedly a very important capability. The advanced technology is the source of profit and competitiveness to enterprises, and at the same time, it is also an important support which helps enterprises adapt market changes. Along with the unceasing renovation of technology of industry, enterprises must 
continually adapt to the technical requirements of market. For SMEs, the technological innovation is all the more a decisive factor for survival and development. In the state of that the economies of scale cannot be achieved, the high technical added value and advanced production process are the keys of that SMEs preserve profit and reduce costs.

Enterprise competitiveness is mainly set for the whole competitiveness of enterprises. It is mainly measured by the performance of production and capital utilization. Enterprise competitiveness is the ultimate expression of comprehensive performance of enterprises, and also a basic dimension of performance evaluation. Through enterprise competitiveness evaluation, the comprehensive performance of enterprises in organization, operation and production can be embody, so enterprise competitiveness evaluation is an essential part of SMEs' performance evaluation.

According to the three dimensions of SMEs' performance evaluation and optimization and the essential requirements of DEA model and CFI model, the index system of SMEs' performance evaluation and optimization is designed as Table 1.

Table 1

Index system of SMEs' performance evaluation and optimization

\begin{tabular}{|c|c|c|c|}
\hline \multirow{2}{*}{ Dimensions } & \multicolumn{2}{|r|}{ DEA Index System } & CFI Index System \\
\hline & $\begin{array}{l}\text { Index } \\
\text { types }\end{array}$ & DEA Indexes & CFI Indexes \\
\hline \multirow{8}{*}{$\begin{array}{l}\text { Dynamic } \\
\text { capability }\end{array}$} & \multirow{4}{*}{ Input } & The cost of adapting to the change of market & $\begin{array}{l}\text { Information systems support the business } \\
\text { processes }\end{array}$ \\
\hline & & Response time of the change of market & Visibility of information in information systems \\
\hline & & The time of market change perception & $\begin{array}{l}\text { Availability of information in information sys- } \\
\text { tems }\end{array}$ \\
\hline & & $\begin{array}{l}\text { The value of resources invested before the } \\
\text { change of market }\end{array}$ & $\begin{array}{l}\text { Quality \& reliability of information in informa- } \\
\text { tion systems }\end{array}$ \\
\hline & \multirow{4}{*}{ Output } & $\begin{array}{l}\text { The rate of sales change of product caused } \\
\text { by the change of market }\end{array}$ & $\begin{array}{l}\text { Usability and functionality of information sys- } \\
\text { tems }\end{array}$ \\
\hline & & $\begin{array}{l}\text { The rate of qualified rate changes of product } \\
\text { caused by the change of market }\end{array}$ & $\begin{array}{l}\text { Short and prompt lead-times in order- } \\
\text { fulfillment process }\end{array}$ \\
\hline & & $\begin{array}{l}\text { The value of resources successfully trans- } \\
\text { formed after the change of market }\end{array}$ & $\begin{array}{l}\text { Adaptiveness of changes in demands and in or- } \\
\text { der backlog }\end{array}$ \\
\hline & & $\begin{array}{l}\text { The value of newly added resources after the } \\
\text { change of market }\end{array}$ & \\
\hline \multirow{6}{*}{$\begin{array}{c}\text { Technological } \\
\text { innovation } \\
\text { capability } \\
\text { (ETIC) }\end{array}$} & \multirow{4}{*}{ Input } & R\&Dfunds inputs & $\begin{array}{l}\text { Training and development of the company's } \\
\text { personnel }\end{array}$ \\
\hline & & Proportion of R\&D staffs & $\begin{array}{l}\text { Innovativeness and performance of research and } \\
\text { development }\end{array}$ \\
\hline & & $\begin{array}{l}\text { Marketing expenditure of new product (per } \\
\text { annum) }\end{array}$ & $\begin{array}{l}\text { Communication between different departments } \\
\text { and hierarchy levels }\end{array}$ \\
\hline & & $\begin{array}{l}\text { The investment for Technology resources ab- } \\
\text { sorption(per annum) }\end{array}$ & Adaptation to knowledge and technology \\
\hline & \multirow{2}{*}{ Output } & The rate of return of new product & Knowledge and technology diffusion \\
\hline & & The sales revenue of new product & $\begin{array}{l}\text { Design and planning of the processes and prod- } \\
\text { ucts }\end{array}$ \\
\hline \multirow{8}{*}{$\begin{array}{c}\text { Enterprise } \\
\text { competitiveness }\end{array}$} & \multirow{5}{*}{ Input } & Total cost of production (per annum) & Reduction of unprofitable time in processes \\
\hline & & Staff quantity & On-time deliveries to customer \\
\hline & & Marketing expenditure (per annum) & $\begin{array}{l}\text { Control and optimization of all types of inven- } \\
\text { tories }\end{array}$ \\
\hline & & The investment of business cooperation & $\begin{array}{l}\text { Leadership and management systems of the } \\
\text { company }\end{array}$ \\
\hline & & The Total Assets of enterprise & $\begin{array}{l}\text { Quality control of products, processes and op- } \\
\text { erations }\end{array}$ \\
\hline & \multirow[t]{3}{*}{ Output } & The product sales revenue (per annum) & $\begin{array}{l}\text { Well defined responsibilities and tasks for each } \\
\text { operation }\end{array}$ \\
\hline & & Market Share & $\begin{array}{l}\text { Utilizing different types of organizing systems } \\
\text { (projects, teams, processes...) }\end{array}$ \\
\hline & & The profit of business cooperation & $\begin{array}{l}\text { Code of conduct and security of data and infor- } \\
\text { mation }\end{array}$ \\
\hline
\end{tabular}




\section{(2) Construction of the DEA model}

According to index system of SMEs' performance evaluation and optimization, the three dimensions need to be evaluated separately by DEA as independent decision points. The resource input and ultimate performance of every decision points can be regarded as the activity that a decision making unit (DMU) output a number of 'products' through input a number of factors of production. There are some differences in details, but their objectives are all for gaining the maximum economic benefits in the activity. Therefore, the evaluating enterprise and each similar competitive enterprise can be regarded as a DMU, and the technical efficiency of evaluating enterprise can be evaluated with the $C^{2} R$ model, and the pure technical efficiency of evaluating enterprise can be evaluated with $B C^{2}$ model, and the scale efficiency of evaluating enterprise can be evaluated with the ratio of technical efficiency to pure technical efficiency. Due to evaluation of each dimension consist of multiple input indexes and multiple output indexes, the subscripts $i$ is used for representing the $i$-th input, and the subscripts $u$ is used for representing the $u$-th output. The number of input indexes and output are supposed separately to be $p$ and $q$.

First, the technical efficiency of enterprises is analyzed with DEA model $\left(D_{C^{2} R}^{\varepsilon}\right)$ which has NonArchimedean infinitesimal presented by Charnes and Cooper.

$$
D_{C^{2} R}^{\varepsilon}\left\{\begin{array}{c}
\min \left[\theta-\varepsilon\left(\sum_{i=1}^{p} s_{i}^{-}+\sum_{u=1}^{q} s_{u}^{+}\right)\right] \\
\sum_{j=k}^{n} x_{i j} \lambda_{j}+s_{i}^{-}=\theta x_{i o} \\
\sum_{j=1}^{n} x_{u j} \lambda_{j}-s_{u}^{+}=y_{o} \\
\lambda_{j}, \quad s_{i}^{-}, s_{u}^{+} \geq 0, \quad j=1,2, \ldots, n, \\
i=1,2, \ldots p, \quad u=1,2, \ldots q
\end{array}\right.
$$

where $\theta$ is the technical efficiency value of the evaluating enterprise in one dimension, $x_{i j}$ and $y_{u j}$ are the $i$-th input and the $u$-th output of the $j$-th DMU, $\lambda_{j}$ is the linear combination of $n$ DMUs, $s_{i}^{-}$is the excess input amount of $i$-th input index, $s_{u}^{+}$is the insufficient output amount of $\mathrm{u}$-th output index.

- Technical efficiency evaluation. If the optimal solution of linear programming model $D_{C^{2} R}^{\varepsilon}$ is $\theta^{0}$, $\lambda_{j}^{0}, s_{i}^{-0}, s_{u}^{+0}$, then the results as follow can be got according to DEA theory.

a) If $\theta^{0}=1, s_{i}^{-0}=0, s_{u}^{+0}=0$, then the $\mathrm{DMU}_{j 0}$ is DEA efficiency, and the $\mathrm{DMU}_{j 0}$ is scale optimum and technical optimum simultaneously in this dimension.

b) If only $\theta^{0}=1$, then $\mathrm{DMU}_{j 0}$ is weak DEA efficiency, and the $\mathrm{DMU}_{j 0}$ can't get scale opti- mum and technical optimum simultaneously in this dimension.

c) If $\theta^{0}<1$, then $\mathrm{DMU}_{j 0}$ is DEA inefficiency, and the $\mathrm{DMU}_{j 0}$ is not scale optimum and technical optimum in this dimension.

- Scale efficiency evaluation. If there exists a value $\lambda_{j}^{0}$ under the condition of which $\sum \lambda_{j}^{0}=1$, then $\mathrm{DMU}_{j 0}$ is constant returns to scale. If there don't exists a value $\lambda_{j}^{0}$ under the condition of which $\sum \lambda_{j}^{0}=1$, and $\sum \lambda_{j}^{0}<1$, then $\mathrm{DMU}_{j 0}$ is increasing returns to scale. If there don't exists a value $\lambda_{j}^{0}$ under the condition of which $\sum \lambda_{j}^{0}=1$, and $\sum \lambda_{j}^{0}>1$, then $\mathrm{DMU}_{j 0}$ is diminishing returns to scale.

- Improvement target. If the evaluate result is weak DEA efficiency or DEA inefficiency, this DMU will need to be improve. If $s_{i}^{-0}>0$ and $s_{u}^{+0}$, it means this DMU's input is excess or output is insufficient. The improvementobjectiveis.

$$
\left\{\begin{array}{c}
\widehat{x}_{i j 0}=\theta^{0} x_{i j 0}-s_{i}^{-0} \\
\widehat{y}_{i j 0}=y_{u j 0}+s_{u}^{+0}
\end{array}\right.
$$

Second, the pure technical efficiency of enterprises in one dimension is analyzed with DEA model $\left(B C^{2}\right)$ presented by Banker.

$$
D_{E C^{2}}\left\{\begin{array}{c}
\min \left[\sigma-\varepsilon\left(\sum_{i=1}^{p} s_{i}^{-}+\sum_{u=1}^{q} s_{u}^{+}\right)\right] \\
\sum_{j=1}^{n} x_{i j} \lambda_{j}+s_{i}^{-}=\sigma x_{i o} \\
\sum_{j=1}^{n} y_{u j} \lambda_{j}-s_{u}^{+}=y_{o} \\
\sum_{j=1}^{n} \lambda_{j}=1 \\
\lambda_{j}, \quad s_{i}^{-}, \quad s_{u}^{+} \geq 0, \quad j=1,2, \ldots, n, \\
i=1,2, \ldots p, \quad u=1,2, \ldots q .
\end{array}\right.
$$

This model fixes the scale efficiency, thus the pure technical efficiency can be evaluated with this model. The optimal solution of the DEA model $\left(B C^{2}\right)$ is assumed to be $\sigma^{0}, \lambda_{j}^{0}, s_{i}^{-0}, s_{u}^{+0}$, then the results can be got according to DEA theory. If $\sigma^{0}=1, s_{i}^{-0}=0$, $s_{u}^{+0}=0$, then $\mathrm{DMU}_{j 0}$ is DEA efficiency, and the pure technical efficiency is optimum. Otherwise, $\mathrm{DMU}_{j 0}$ is DEA inefficiency the pure technical efficiency is not optimum.

If the DEA evaluation result of evaluating enterprise in one dimension is DEA efficiency, it proves the operational efficiency of evaluating enterprise is good. The evaluating enterprise only need to increase appropriately the resource input in the critical index determined by CFI model to impel the critical index to get back into the normal state, but not adjust greatly the existing input-output framework. 
If the DEA evaluation result of evaluating enterprise in one dimension is that the pure technical efficiency of evaluating enterprise is optimum, the resource input in this dimension need to be adjusted. According to the different results of scale efficiency evaluation, there are two cases as follow.

a) Increasing returns to scale. In this cases, the evaluating enterprise need to input lots of resources in the critical index determined by CFI model, and try to input more resources in normal index with lower score to enlarge the overall scale in the dimension, and then to increase efficiency in the dimension.

b) Diminishing returns to scale. In this cases, the evaluating enterprise only need to input appropriately some resources in the critical index determined by CFI model, and give priority to the normal index of this dimension in selecting objects of decrease resources.

If the DEA evaluation result of evaluating enterprise in one dimension is that the scale efficiency of evaluating enterprise is optimum, it proves there are some problems in resources input structure of this dimension. Therefore, the evaluating enterprise can consider adjusting resource structure within the dimension based on the results of CFI evaluation.

If the DEA evaluation result of evaluating enterprise in one dimension is DEA inefficiency, the evaluating enterprise can consider balancing resource within the dimension, and adjusting resource input structure while increasing or reducing the resource input based on the results of scale efficiency evaluation. Then the evaluating enterprise needs to readjust operation structure and organization structure, and carry forward the organizational restructuring and strategic remanufacturing.

\section{(3) Construction of the CFI model}

The Critical Factor Index (CFI) method is a measurement tool to indicate which attribute of a business process is critical and which is not, based on the experience and expectations of the company's employees, customers or business partners [10]. In the current business environment strategic decision marking and fast adaption requires a reliable and efficient method to sense and respond customer satisfaction for management purpose [11]. By the detection and abstraction of the most critical attributes which are affecting the business performance of a company both on a current moment and future perspective (5-10 years), the CFI method is able to conduct and interpret tacit knowledge which existing inside or outside of company to take deliberate strategic steps in a short period of time [12]. The key factors can be given as blew:
Gap Index - helps to understand the gap between the expectation and experience of a particular attribute, therefore to clarify if the company's expectations are correct and corresponding to the reality.

$$
\begin{aligned}
& \text { Gap index }=\mid(\text { avg of experience } \\
& \text { - average of expectation }) / 10-1 \mid \text {. }
\end{aligned}
$$

Direction of Development Index - demonstrates the actual positive or negative change of an attribute's performance. The index provides us with the information about the actual direction of the company's development.

$$
\begin{gathered}
\text { Direction of development }= \\
\mid(\text { Better } \%-\text { Worse } \%) / 100-1 \mid .
\end{gathered}
$$

Importance Index - demonstrates the level of importance of an attribute among the others. The index reflects the actual expectations of the company regarding an attribute. Anyhow, the expectation may not correspond to the experience.

Important index = avg. of expectation/10.

Performance Index - reflects the value of an attribute's performance based on the actual experience of the respondents. In the result we can see either an attribute has performed well or not and make the conclusion about the attribute importance.

Performance index $=$ avg. of experience/10.

Standard Deviation Expectation Index - reflects the fact if the respondents have similar or controversial meaning regarding all the attributes' expectations.

$$
\begin{gathered}
\text { SD expectation index }= \\
\left(\frac{\mathrm{SD} \text { of expectation }}{10}\right)+1 .
\end{gathered}
$$

Standard Deviation Experience Index - reflects the fact if the respondents have similar or controversial meaning regarding all the attributes' experiences.

$$
\begin{gathered}
\mathrm{SD} \text { experience index }= \\
\left(\frac{\mathrm{SD} \text { of experience }}{10}\right)+1 .
\end{gathered}
$$

\section{Operational competitiveness analysis of case study}

The main role of the case study is to present the results of the DEA and CFI evaluations as well as to show method validation such as how it was organized. In other words, Results section reflects empirical data and the practical experience gained during the research. The case companies took part in the research demonstrates the evaluation and performance 
of research models. The basic information about the participants, their field of activity and number of respondents is necessary for the research creditability and forms a deeper understanding of the research area. The company information represented in research is confidential; therefore the official names of the case companies will not be appeared in this case study.

\section{(1) CFI analysis}

By analyzing data from case company and combining CFI method with index system of SMEs' performance evaluation, all critical factors have been grouped and evaluated into three dimensions: Dynamic capability, Technological innovation capability and Enterprise competitiveness; the data is presented in the Fig. 1.

In the dimension of dynamic capability, the factor of "Short and prompt lead-times in order fulfillment process" reflects huge uncertainty for its trend, it does not show creditability of the model research, this factor should be paid more attention for its uncertainties. In this dimension group, most of critical factors reflect better performance in future except the factor "Availability of information and information system", this factor should be taken more awareness and importance by managers for its future perspective.

In the dimension of technological innovation capability, most critical factors keep their level and general performance is slightly better in future, however the factor "Adaptation to knowledge and technology" reflects deteriorated performance in future perspective, so this factor should be taken into consideration in order to keep its level and ensure its better performance in the future.

The general performance in dimension of enterprise competitiveness deteriorates in the future regarding to most of critical factors. Typically, two critical factors "On-time deliveries to customers" and "well defined responsibilities and tasks for each operation" have worst performance and these two critical factors have to be awaked and improved by decision makers for their future perspective and importance.

\section{(2) DEA analysis}

For further validating the effectiveness of the new SMEs' performance evaluation and optimization system, this paper has surveyed 5 SMEs, among which the enterprise $\mathrm{A}$ is as the research sample of this paper. The DEA result which is calculated by DEAP software is showed in Table 2 as follow.

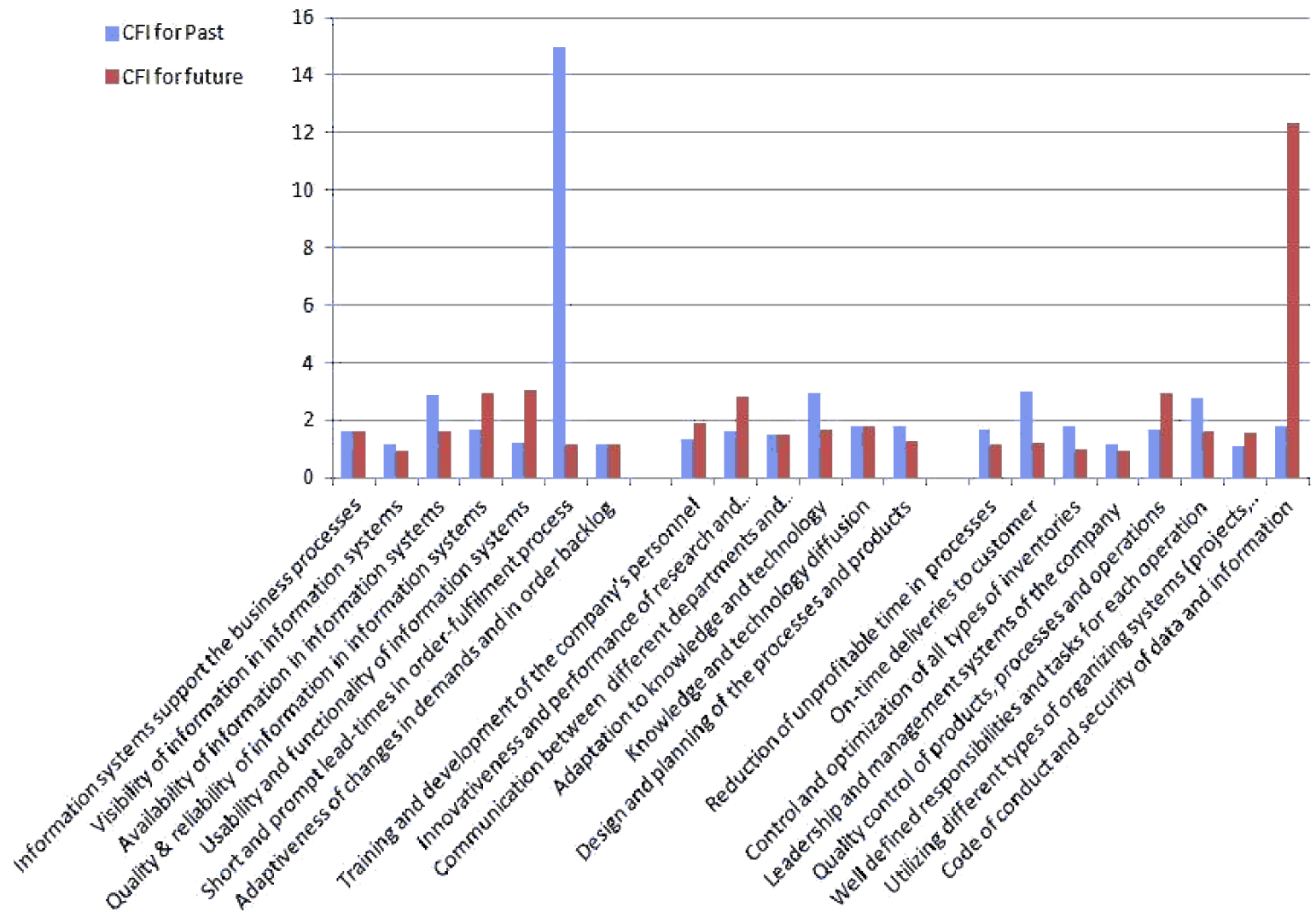

Fig. 1. The data result of CFI analysis [12]. 
Management and Production Engineering Review

Table 2

The DEA analysis of enterprise A.

\begin{tabular}{|c|c|c|c|c|c|c|c|c|c|c|}
\hline Dimensions & $\mathrm{DMU}$ & $\theta^{0}$ & $\sigma^{0}$ & $s^{0}$ & $s_{1}^{0-}$ & $s_{2}^{0-}$ & $s_{1}^{0+}$ & $s_{2}^{0+}$ & $s_{3}^{0+}$ & scale efficiency \\
\hline \multirow{5}{*}{ Dynamic capability } & $\mathrm{A}$ & 0.343 & 1.000 & 0.343 & 0.071 & - & 0.000 & 6.000 & - & increase \\
\hline & B & 1.000 & 1.000 & 1.000 & 0.000 & - & 0.000 & 0.000 & - & - \\
\hline & $\mathrm{C}$ & 0.229 & 1.000 & 0.229 & 0.213 & - & 0.000 & 6.000 & - & increase \\
\hline & $\mathrm{D}$ & 0.160 & 1.000 & 0.160 & 0.300 & - & 0.000 & 4.000 & - & increase \\
\hline & $\mathrm{E}$ & 0.800 & 1.000 & 0.800 & 0.000 & - & 0.000 & 0.000 & - & increase \\
\hline \multirow{5}{*}{$\begin{array}{l}\text { Technological } \\
\text { innovation } \\
\text { capability } \\
\text { (ETIC) }\end{array}$} & $\mathrm{A}$ & 1.000 & 1.000 & 1.000 & 0.000 & 0.000 & 0.000 & 0.000 & 0.000 & - \\
\hline & $\mathrm{B}$ & 1.000 & 1.000 & 1.000 & 0.000 & 0.000 & 0.000 & 0.000 & 0.000 & - \\
\hline & $\mathrm{C}$ & 1.000 & 1.000 & 1.000 & 0.000 & 0.000 & 0.000 & 0.000 & 0.000 & - \\
\hline & $\mathrm{D}$ & 0.000 & 1.000 & 0.000 & 0.000 & 0.000 & 0.000 & 0.000 & 0.000 & increase \\
\hline & $\mathrm{E}$ & 0.270 & 0.270 & 1.000 & 0.000 & 0.000 & 0.052 & 0.000 & 0.000 & - \\
\hline \multirow{5}{*}{$\begin{array}{c}\text { Enterprise } \\
\text { competitiveness }\end{array}$} & $\mathrm{A}$ & 0.543 & 0.657 & 0.827 & 0.000 & 0.000 & 0.053 & 0.000 & 0.008 & increase \\
\hline & $\mathrm{B}$ & 0.669 & 0.669 & 0.999 & 0.000 & 0.000 & 23.934 & 0.000 & 0.976 & increase \\
\hline & $\mathrm{C}$ & 1.000 & 1.000 & 1.000 & 0.000 & 0.000 & 0.000 & 0.000 & 0.000 & - \\
\hline & $\mathrm{D}$ & 1.000 & 1.000 & 1.000 & 0.000 & 0.000 & 0.000 & 0.000 & 0.000 & - \\
\hline & $\mathrm{E}$ & 1.000 & 1.000 & 1.000 & 0.000 & 0.000 & 0.000 & 0.000 & 0.000 & - \\
\hline
\end{tabular}

According to the DEA results, the enterprise A is DEA efficiency in ETIC dimension, but in dynamic capability dimension, enterprise $\mathrm{A}$ is pure technical efficiency, and in enterprise competitiveness dimension, enterprise A is DEA inefficiency. Therefore, the conclusioncan be got as follow.

- In dynamic capability dimension, the pure technical efficiencyof enterprise $\mathrm{A}$ is optimum, and the result of scale efficiency evaluation is increasing returns to scale. The enterprise A need to input lots of resources in the critical index determined by CFI model, and try to input more resources in normal index with lower score to enlarge the overall scale in the dimension, and then to increase efficiency in the dimension.

- In enterprise competitiveness dimension, the enterprise A is DEA inefficiency, and the result of scale efficiency evaluation is increasing returns to scale. The enterprise A need to input lots of resources in the critical index determined by CFI model, and adjusting resource input structure while increasing the resource input. Then the enterprise A needs to readjust operation structure and organization structure, and carry forward the organizational restructuring and strategic remanufacturing.

\section{Discussion}

SMEs are the hard core of the equipment manufacturing industry of developed countries, and it is also the crucial driving power of economic development in Europe and America. Therefore, the method of SMEs' performance evaluation and optimization is the focal point of performance evaluation research field. At present, there are various performance evaluation methods in performance evaluation research field, among which the more common methods are Data Envelopment Analysis (DEA), Analytic Hierarchy Process (AHP), and so on. These methods are with different characteristics and different disadvantages. In comparison, DEA is more objective, but this method is always restricted by the authenticity and statistic standard of data due to the high requirements of data quality. In addition DEA can only analyze the efficiency of production or operation, but can't combine with corporate strategy and leadership. CFI method is a kind of evaluation method based on AHP. Similar to AHP, CFI method is very easy to obtain data and combine with corporate strategy and leader thought, but this method is always affected by the validity of data and the personal subjective factors of survey respondents. The applications scope of CFI is limited, and it is incomparable. The new SMEs' performance evaluation and optimization system which combine the DEA and CFI presented by this paper has combined the advantages of the two evaluation methods. This system uses DEA in dimension level to evaluate the performance of dimensions and support the following resources allocation optimization based on the comparison of the target enterprise and its major competitors. And then the system uses CFI in Index level to evaluate and optimize the resource allocation of dimensions. It is very clear that the new SMEs' performance evaluation and optimization system presented by this paper can compare the current situation of indexes with major competitors and enterprise strategic objectives simultaneously, and it 
can evaluate and optimize the SMEs' performance in the whole process.

Practice is an important way to test the validity of a new method. The DEA and CFI method has been tested by a lot of case study, and accepted by academia. For further validating the effectiveness of the new SMEs' performance evaluation and optimization system, this paper has surveyed 5 SMEs. These 5 SMEs all belong to industrial manufacturing enterprises, and have a certain degree of similarity in scale, organization structure and business model. Therefore, these 5 SMEs fit to the requirements of DEA and CFI. The comparison between the analysis results and the feedback result of 5 SMEs shows that the new system has validity in the performance evaluation and optimization practice, and it can provide enterprises with efficient proposals of resource optimization. This research will further large-scale use the method in future research to further test and verify it.

\section{Conclusion}

In this paper, a new SMEs' performance evaluation and optimization system has been built by the research of combining effectiveness of DEA performance evaluation model and resource-utilization of CFI performance evaluation model. The key focus is to combine and leverage two models together with comparing difference of effectiveness in enterprise and its main competitors within each dimension in order to perceive inefficiency in the enterprise and support CFI optimization strategy. By applying CFI and DEA evaluation methods, the resource allocation and utilization within the enterprise can be balanced and optimized. Therefore, the system in theory provides valuable evaluation and optimization capabilities for enterprises' resource allocation and utilization. To access creditability of the system, one mid-sized case company has been investigated with in-depth research of 5 SMEs, the case results show that the new system has high degree of validity in reality, which provides efficient supports for performance evaluation and decision optimization in enterprises.

\section{References}

[1] Ayyagari M., Beck T., Demirguc-Kunt A., Small and medium enterprises across the globe, Small Business Economics, 29, 4, 415-434, 2007.
[2] Storey D.J., Entrepreneurship, Small and Medium Sized Enterprises and Public Policy, Acs ZJ \&Audretsch DB (eds) Handbook of Entrepreneurship Research, Dordrecht, International Handbook of Entrepreneurship Research, 473-511, 2003.

[3] Tagliavini M., Ravarini A., Antonelli A., An evaluation model for electronic commerce activities within SMEs, Information Technology and Management, 2, 2, 211-230, 2001.

[4] Beck T., Demirguc-Kunt A., Levine R., SMEs, growth, and poverty: cross-country evidence, Journal ofEconomicGrowth 10(3): 199-229, 2005.

[5] Reynolds P.D., New and small firms in expanding markets, Small Business Economics, 9, 1, 79-84, 1997.

[6] Robson P.J.A., Bennett R.J., SME Growth: The Relationship with Business Advice and External Collaboration, Small Business Economics, 15, 3, 193208, 2000 .

[7] Blili S., Raymond L., Information technology: threats and opportunities for small and mediumsized enterprises, Int. J. Inf. Manage, 13, 6, 439-448, 1993.

[8] Takala J., Satayapaisal A., Wiriyacosol S., Chansangavej C: Critical performance attributes of thai automotive supply chains, 3, 2, 36-48, DOI: 10.2478/v10270-012-0014-o, June 2012.

[9] Schatten A., Schiefer J., Agile business process management with sense and respond, International Conference on e-Business Engineering2007 proceedings of the international conference in Hong Kong, IEEE Computer Society, Washington, pp. 319-322, 2007.

[10] Ranta J-M., Takala J., A holistic method for finding out critical features of industry maintenance services, International Journal of Services and Standards by InderscienceEnterprises Ltd., UK, 3, 3, 312-325, 2007.

[11] Menguc B., Auh S., Shih E., Transformational leadership and market orientation: Implications for the implementation of competitive strategies and business unit performance, Journal of Business Research, 60, 4, 314-321, 2007.

[12] Nadler D., Takala J., The development of the CFI method to measure the performance of business processes based on real life expectations and experiences, International Conference on Innovation and Management, ICIM2010, December 4-5, Wuhan, China, 2010. 